\title{
TAMAÑOS DE ALVÉOLO Y DIFERENTES LÁMINAS DE RIEGO EN OBTENCIÓN DE PLÁNTULAS DE TOMATE
}

\section{ALVEOLUS SIZE AND DIFFERENT WATERING LEVELS IN THE PRODUCTION OF TOMATO SEEDLINGS}

Fabián Andrés Wilches-Rojas ${ }^{1}$ Javier Giovanni Álvarez-Herrera ${ }^{2}$ Helber Enrique Balaguera-López ${ }^{3}$

\section{RESUMEN}

En el cultivo de tomate es importante el manejo de agua, de el depende el éxito o fracaso del mismo. E desconocimiento de la cantidad de agua requerida por el cultivo en su etapa de germinación y posterior propagación, así como el tamaño óptimo de alvéolo de la bandeja para un mejor rendimiento, es un hecho en nuestro medio. Consecuentemente, se evaluó el efecto del tamaño de alvéolo y diferentes láminas de riego en cuatro híbridos de tomate larga vida, sembrados en turba como sustrato, utilizando un diseño estadístico en bloques al azar con cuatro repeticiones, que correspondieron a los tamaños de alvéolos y 16 tratamientos que fueron la combinación de los coeficientes o láminas de riego $(1,0 ; 1,4 ; 1,8 ; 2,2)$ y los híbridos (Sheila, Astona, Indaba, Daniela 593), para un total de 64 unidades

\footnotetext{
${ }^{1}$ Ingeniero Agrónomo. Grupo de Investigaciones Agrícolas, Facultad de Ciencias Agropecuarias, Universidad Pedagógica y Tecnológica de Colombia, Tunja. e-mail: faandres83@hotmail.com.

2 Profesor asistente. Grupo de Investigaciones Agrícolas, Facultad de Ciencias Agropecuarias, Universidad Pedagógica y Tecnológica de Colombia, Tunja. e-mail: jagial@mail.com.

${ }^{3}$ Ingeniero Agrónomo. Grupo de Investigaciones Agrícolas, Facultad de Ciencias Agropecuarias, Universidad Pedagógica y Tecnológica de Colombia, Tunja. e-mail: enrique_balaguera@yahoo.com.
}

experimentales. Los resultados mostraron que el mejor coeficiente (lámina) para la germinación de tomate fue el de 2,2. Los mejores tamaños de bandeja fueron el de 72 y 144 alvéolos. El mejor tratamiento fue el híbrido Daniela 593, con los coeficientes de 2,2; 1,8 o 1,4 sembrado en bandejas de 72 alvéolos, el cual presentó un alto porcentaje de enraizamiento y una mayor respuesta en producción de fitomasa fresca y seca. Adecuados contenidos de humedad debidos a la lámina aplicada y al tamaño de alvéolo optimizan el tiempo medio de germinación (TMG) y la velocidad media de germinación (VMG). El híbrido Sheila presentó el mayor porcentaje de germinación.

Palabras clave: Lycopersicon esculentum Mill, germinación, híbridos, sustrato, propagación.

\section{SUMMARY}

Water management is very important in the tomato culture, the success or failure of the crop depends on it. Unknown facts, under our conditions, are the amount of water required by the plant during germination and subsequent propagation, as well as the optimal tray alveolus size for a better future yield. The effect of the alveolus size and of different water tables in four tomato long life hybrids, planted in peat as substrate was evaluated. A statistical design of random blocks with four repetitions was employed being the variables alveolus sizes and 16 treatments that combined water tables or coefficients of irrigation $(1.0 ; 1.4 ; 1.8 ; 2.2)$ and hybrids (Sheila, Astona, Indaba, Daniela 593) for a total of 64 
experimental units (UE). The results showed that the best coefficient (water table) for the tomato seed germination was the 2.2. The optimal tray sizes encountered were those having 72 and 144 alveoli. The best performance was obtained with the hybrid Daniela 593 with water coefficients of $2.2 ; 1.8$ or 1.4 , planted in trays of 72 alveoli. This hybrid presented a high rooting percentage and an increased response of production of fresh and dry mass. Appropriate moisture content, guaranteed by the water table applied and the alveolus size, optimized the medium germination time (MGT) and the medium germination velocity (MGV). The highest germination percentage was obtained with the hybrid Sheila.

Key words: Lycopersicon esculentum Mill, germination, hybrids, substrate, propagation.

\section{INTRODUCCIÓN}

El tomate (L. esculentum Mill) es una planta originaria de Perú, norte de Chile, Ecuador y México, países en donde se encuentran varias formas silvestres, cultivado desde el nivel del mar hasta los 2000msnm a libre exposición y hasta $2700 \mathrm{msnm}$ bajo cubierta. El tomate, se cultivaba, en principio, como planta de adorno, pero a partir de 1900 , se extendió el cultivo como alimento humano (Mondoñedo, 1984).

Actualmente es la especie hortícola más sembrada en el mundo entero y, en Colombia, la segunda después de la arveja y primera en volumen, consumo y valor de la producción. El área sembrada en el año 2005 fue de 14.659ha y la producción fue de 411.994t (Observatorio de Finanzas Rurales, 2005).

La creciente demanda de plántulas vigorosas con un sistema radicular sin disturbar, la aparición de enfermedades como Damping-off, tizón tardío, virosis, bacteriosis, entre otras y el alto costo de las semillas de tomate mejoradas genéticamente, hacen necesaria la utilización de sistemas de producción de plántulas en bandejas de germinación, donde se utilizan sustratos enriquecidos con fertilizantes (Castilla, 1995).

El tomate presenta tres momentos críticos de necesidad hídrica: emergencia de plántulas, floración y cuando los frutos han alcanzado una quinta parte de su crecimiento (Manjarrez, 1980); sin embargo, las necesidades hídricas en la etapa de germinación no están establecidas, de tal forma que no se conocen las dosis adecuadas que permitan mayor aprovechamiento del agua, situación que se traduce en un uso inadecuado del recurso hídrico y disminución en el número y calidad de las plántulas de tomate.

La variación en la capacidad de almacenamiento de sustrato y de humedad origina plántulas con distinto vigor, por lo tanto, el uso de bandejas de germinación con diferentes tamaños de alvéolos disminuye la homogeneidad de las plántulas al momento del trasplante (González E Hernández, 2000). Sarmiento et al. (2007) evaluaron la siembra en bandejas de diferente número de alvéolos, con semillas previamente sometidas a diferentes tiempos de imbibición y encontraron que la bandeja de 72 alvéolos produjo las plántulas más vigorosas.

El método más utilizado para obtener plantas sanas y vigorosas es a través de la germinación de semillas en bandejas plásticas de confinamiento. Esto permite un ahorro de semilla, mejor planificación de siembras, calidad y uniformidad de plántulas, ahorro de sustrato, facilidad para movilizar las plántulas, fácil remoción y evita la destrucción de la raíz de las plantas al momento del trasplante (Jaramillo et al. 2006a).

Fernández-Bravo et al. (2006) evaluaron la germinación de tomate Riogrande utilizando diferentes sustratos en bandeja de germinación y encontraron que las semillas respondieron favorablemente al proceso germinativo en el sustrato turba, seguido de mezcla de compost de cachaza de caña de azúcar y aserrín de coco molida en relación 2:1.

González E Hernández (2000) realizaron el estudio de estimación de las necesidades hídricas del tomate a libre exposición, en la zona Henequenera de Yucatán, con cinco tratamientos, que consistieron en la aplicación de diferentes volúmenes de agua. El rendimiento más elevado en las categorías total, comercial y de tercera, se logró con el coeficiente 0,8 con 35,8; 23,9 y 12,5 t.ha ${ }^{-1}$, respectivamente.

Por las razones expuestas anteriormente, el objetivo de este trabajo fue evaluar el efecto del tamaño de alvéolo de bandejas de germinación y de diferentes láminas de riego en la obtención de plántulas de híbridos de tomate larga vida, para asegurar una mejor calidad del material vegetal en la etapa de vivero y posteriormente en campo. 


\section{MATERIALES Y MÉTODOS}

El estudio, se realizó en el invernadero de vidrio de la Facultad de Ciencias Agropecuarias de la Universidad Pedagógica y Tecnológica de Colombia en la ciudad de Tunja, a una altitud de $2782 \mathrm{msnm}$ y longitud $73^{\circ} 23^{\prime}$ oeste, latitud $5^{\circ} 32^{\prime}$ norte. La temperatura promedio dentro del invernadero fue de $20^{\circ} \mathrm{C}$ y la humedad relativa (HR) del 65\%.
Como material vegetal, se emplearon los híbridos indeterminados de tomate larga vida tipo milano Sheila, Astona, Indaba y Daniela 593, los cuales se seleccionaron y se sembraron en cuatro bandejas de polietileno de 72 (B1), 144 (B2), 128 (B3) y 200 (B4) alvéolos respectivamente (Tabla 1). La lámina de riego suministrada correspondió a cuatro coeficientes de la evaporación (Ev), el sustrato que se utilizó fue Turba rubia Canadiense (TC), la cual esta enriquecida con Ca: 6,24; Mg: 4,3 y K: 3,5cmol $\cdot k g$ de sustrato.

Tabla 1. Características de las bandejas de polietileno utilizadas para la germinación de híbridos de tomate (L. esculentum Mill), bajo diversas láminas de riego, sembrados en diferentes tamaños de alvéolos.

\begin{tabular}{|c|c|c|c|c|c|c|c|c|c|}
\hline REFERENCIA & CALIBRE & $\begin{array}{c}\text { LADO } \\
(\mathbf{c m}) \\
\text { Alvéolo }\end{array}$ & $\begin{array}{c}\text { LADO } \\
\mathbf{( \mathbf { c m } )}\end{array}$ & $\begin{array}{c}\text { Alvéolo } \\
\left(\mathbf{m}^{2}\right) \\
\text { Alvéolo }\end{array}$ & $\begin{array}{c}\text { PROF } \\
\mathbf{c m}\end{array}$ & $\begin{array}{c}\text { VOL } \\
\mathbf{c c}\end{array}$ & $\begin{array}{c}\text { LADO } \\
(\mathbf{m}) \\
\text { Bandeja }\end{array}$ & $\begin{array}{c}\text { LADO } \\
\mathbf{( m )} \\
\text { Bandeja }\end{array}$ & $\begin{array}{c}\text { AREA } \\
\left(\mathbf{m}^{2}\right) \\
\text { Bandeja }\end{array}$ \\
\hline B1=Bandeja X 72 & 55 & 3,5 & 3,5 & 0,00122 & 5,8 & 51 & 0,55 & 0,29 & 0,16 \\
\hline B2=Bandeja X 144 & 55 & 3,1 & 3,1 & 0,00096 & 5,9 & 30 & 0,55 & 0,30 & 0,17 \\
\hline B3=Bandeja X 128 & 55 & 3,0 & 3,0 & 0,00090 & 5,0 & 25 & 0,55 & 0,29 & 0,16 \\
\hline B4=Bandeja X 200 & 55 & 2,2 & 2,2 & 0,000484 & 2,5 & 7.5 & 0,55 & 0,29 & 0,16 \\
\hline
\end{tabular}

Fuente: adaptado de www.elsemillero.net.

El diseño implementado fue de bloques al azar; cuatro bloques correspondientes a los tamaños de alvéolo y 16 tratamientos en un factorial de $4 \times 4$, para las láminas de riego y los híbridos, respectivamente, para un total de 64 unidades experimentales (UE). Cada UE estuvo compuesta por tres semillas al momento de la siembra y por una planta después de la emergencia. Para la determinación de la lámina de riego, la evaporación se multiplicó por los coeficientes 1,0; 1,4; 1,8 y 2,2, que fueron factores multiplicadores de un tanque simulador del evaporímetro.

La Ev se midió con un evaporímetro plástico a escala del tanque tipo A con dimensiones de $29 \mathrm{~cm}$ de diámetro y 6,1 cm de profundidad; se instaló dentro del invernadero y se hicieron lecturas diarias. Para el suministro de agua a la planta, se utilizaron jeringas de 5 y $20 \mathrm{~mL}$, con el fin de tener una mayor exactitud en las cantidades aplicadas.
Las aplicaciones, se realizaron con base en la siguiente fórmula:

$$
\text { Lámina }=\frac{\operatorname{Etp} * \mathrm{C} * \mathrm{~A}}{\eta_{\mathrm{r}}}
$$

En donde, Etp = evapotranspiración en mm medida en el tanque evaporímetro; $\mathrm{C}=$ coeficiente multiplicador; $\mathrm{A}$ $=$ área del alvéolo; $\eta_{\mathrm{r}}=$ eficiencia del riego $(0,9)$.

Las variables de respuesta medidas durante la germinación (Tabla 2) fueron la velocidad de germinación media (VMG), tiempo medio de germinación (TMG) y el porcentaje de germinación (PG), para lo cual se tuvo en cuenta el número de días que necesito cada semilla para iniciar el proceso de germinación. 
Tabla 2. Variables de germinación medidas en híbridos de tomate (L. esculentum Mill), con diversas láminas de riego y en diferentes tamaños de alvéolos.

\begin{tabular}{|c|c|c|}
\hline Variable & Ecuación & Unidades \\
\hline $\begin{array}{c}\text { Velocidad media de } \\
\text { germinación }\end{array}$ & $\mathrm{VMG}=\sum\left(\frac{\mathrm{n}_{\mathrm{i}}}{\mathrm{t}_{\mathrm{i}}}\right)$ & Semillas germinadas /día \\
\hline $\begin{array}{c}\text { Tiempo medio de } \\
\text { germinación }\end{array}$ & $\mathrm{TMG}=\frac{\mathrm{N}^{*}\left(\mathrm{~A}_{1}+\mathrm{A}_{2}+\mathrm{A}_{\mathrm{X}}\right)}{\left(\mathrm{A}_{1} * \mathrm{~T}_{1}+\mathrm{A}_{2} * \mathrm{~T}_{2}+\mathrm{A}_{\mathrm{x}} * \mathrm{~T}_{\mathrm{x}}\right)}$ & días \\
\hline Porcentaje de germinación & $\mathrm{PG}=\left(\frac{\mathrm{N}}{\mathrm{N}_{\mathrm{S}}}\right) * 100$ & $\%$ \\
\hline
\end{tabular}

$\mathrm{ni}=$ Número de semillas germinadas en el i-ésimo día;

$\mathrm{ti}=$ Tiempo en días, para la germinación en el i-ésimo día.

$\mathrm{N}=$ número de semillas germinadas;

$A 1, A 2, \ldots, A x$ : número de semillas germinadas en el día 1, en el día 2 , y en el día $x$;

$\mathrm{T} 1, \mathrm{~T} 2, \ldots, \mathrm{Tx}$ : número de días entre la siembra y el primer día 1 de germinación, entre el día 2 y entre el día $\mathrm{x}$.

En la etapa de plántula, se midió área foliar, mediante el integrador de área foliar Li-Cor ${ }^{\circledR}$ 3000A (Li-Cor, USA); fitomasa fresca de raíz, tallo y hojas; fitomasa seca de raíz, tallo y hojas después de someter las plantas a $70^{\circ} \mathrm{C}$ durante 48 h; longitud de raíz principal; diámetro del tallo usando un calibrador de vernier y altura final.

Se realizaron los análisis de varianza (Anova), con el fin de determinar la existencia de diferencias entre tratamientos; así mismo, se usó la prueba de comparación múltiple de medias de Tukey al $5 \%$.

\section{RESULTADOS Y DISCUSIÓN}

Porcentaje de germinación (PG): se presentaron diferencias altamente significativas, lográndose la mayor respuesta, con T2, T5, T7, T8, T9, T10, T13 y T14 frente a la menor obtenida con T11 (Figura 1B). Sin embargo, esta respuesta se debe al efecto de heterosis (Figura $1 \mathrm{~A})$, ya que las láminas por sí solas no presentaron diferencias, al igual que los tamaños de alvéolos. No obstante, el PG tuvo una relación directa con el aumento en la lámina aplicada y el tamaño de alvéolo, factor que favorece la obtención de mayor número de plántulas.

Es posible que el híbrido Sheila expresara un mayor PG condicionado genéticamente; junto a esto se observa que, a medida que se aumenta la lámina y el tamaño de alvéolo se asegura mayor humedad que incrementa el proceso germinativo. Semillas que se hidratan permiten que se active el proceso metabólico relacionado con el proceso pregerminativo y la auto reparación enzimática de las membranas celulares (Burgass \& Powell, 1984). De esta manera, se asegura una mayor germinación al disminuir el posible efecto ocasionado por procesos de quiescencia (Khan, 1992).

Por otro lado, Jaramillo et al. (2006a) afirman que de acuerdo al material vegetal utilizado varía el porcentaje de germinación, entre un 93 a un $97 \%$ en híbridos y de un 85 a un $95 \%$ en variedades, en condiciones óptimas.

Tiempo medio de germinación (TMG): entre tratamientos, se presentan diferencias estadísticas: el T4 necesitó menos días para activar la germinación, mientras que la mayor duración en días fue con el T10 (Figura 1C). En semillas de tomate, se encontró la expresión de dos genes relacionados con el crecimiento de la radícula y degradación metabólica del endospermo (Chen $\varepsilon$ Bradford, 2000), proceso regido por las giberelinas, cuya síntesis y acumulación depende de la presencia de agua en la semilla (Talón, 1993), por tanto, un contenido adecuado de humedad en la semilla garantiza que el proceso germinativo se lleve a cabo en menor tiempo y esto, a su vez, le permite al productor 


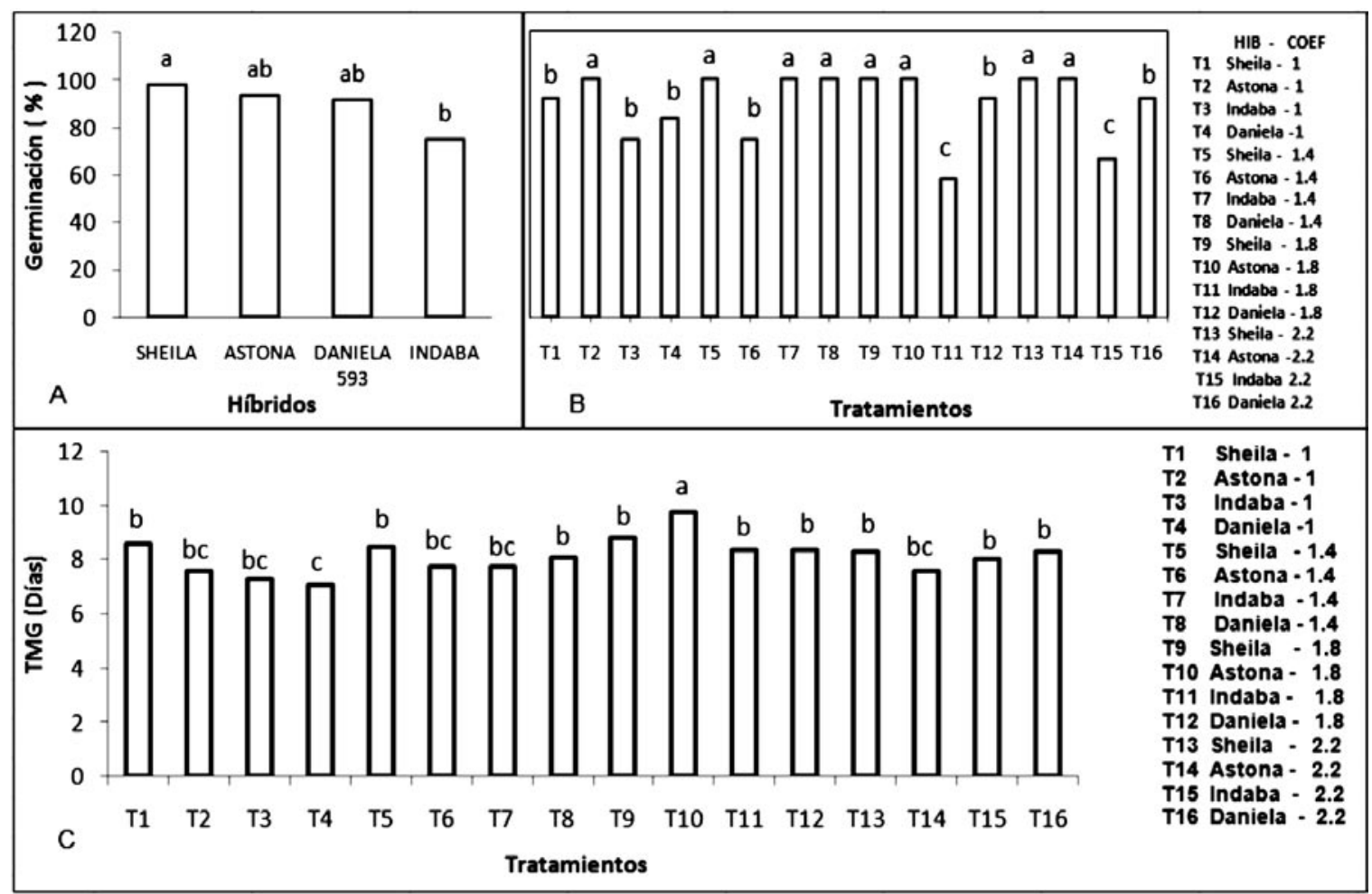

Figura 1. Porcentaje de germinación y tiempo medio de germinación de híbridos de tomate (L. esculentum Mill) con diferentes láminas de riego, sembrados en diversos tamaños de alvéolos.

disminuir el tiempo en la etapa de propagación y ser mas eficiente en la obtención de plántulas.

El TMG no presentó diferencias significativas respecto a los híbridos, lo que obedece a que el TMG no se vió afectado por las características genéticas de cada cultivar. Los tamaños de alvéolo de B1, B2 y B3 mostraron diferencias altamente significativas respecto a B4 pero no entre sí (Figura 2A). De acuerdo a lo anterior, estos tamaños de alvéolo representan mayor área y volumen en comparación con B4 permitiendo mayor cantidad de sustrato y, consecuentemente, mayor retención de humedad y cantidad de nutrientes, lo que proporciona condiciones favorables para la germinación.

Al evaluar las láminas de riego, se encontraron diferencias significativas entre la lámina 1,0 y las láminas 1,4 y 2,2; éstas, a su vez, mostraron diferencias significativas con la lámina 1,8 (Figura 2B).

Para la germinación de las semillas de tomate es suficiente mantener el sustrato con niveles adecuados de humedad. La entrada de agua en el interior de la semilla, se debe exclusivamente a una diferencia de potencial hídrico entre ésta y el medio que le rodea. En condiciones normales, el potencial hídrico es menor en las semillas secas que en el medio exterior. Por ello, hasta que emerge la radícula, el agua llega al embrión a través de las paredes celulares de la cubierta seminal, siempre a favor de un gradiente de potencial hídrico, es decir, cuando se suplen sus necesidades de agua. Aunque es necesaria el agua para la rehidratación de las semillas, un exceso de la misma actuaría desfavorablemente para la germinación, pues dificultaría la llegada de oxígeno al embrión (Pérez-García \& Martínez-Laborde, 1994). La semilla de tomate se tarda entre 4 y 7 días para germinar en condiciones óptimas (Jaramillo et al. 2006b).

Velocidad media de germinación (VMG): mostró diferencias significativas entre tratamientos, pero se le atribuyen a la lámina de riego y no a los híbridos, debido a que éstos no presentaron diferencias estadísticas. La lámina de 1,0 tuvo la mayor respuesta frente a la lámina de 1,8 (Figura 2D). El T4, correspondiente al 


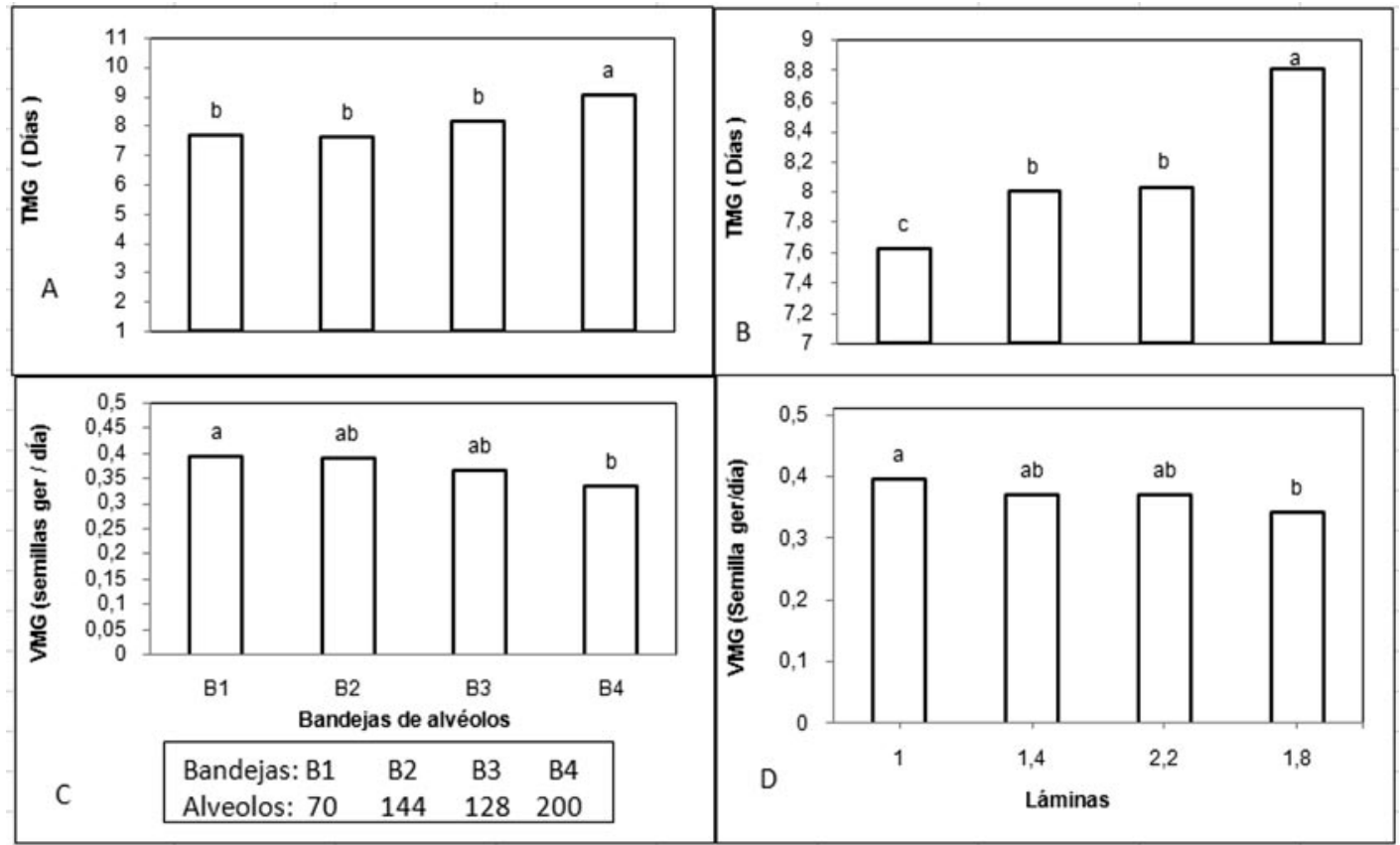

Figura 2. Velocidad media y tiempo medio de germinación en híbridos de tomate (L. esculentum Mill), con diferentes láminas de riego, sembrados en diversos tamaños de alvéolos.

híbrido Daniela 593 con la lámina 1,0 obtuvo la mayor VMG, con 0,41 semillas germinadas/día, seguido de T3 y T2, los cuales mostraron diferencias significativas con los demás tratamientos. El menor número de semillas germinadas/día, se logró con el T10 (0,3).

Para los tamaños de alvéolo, se encontró que B1 indujo mayor VMG con diferencias significativas respecto a B4 (Figura 2C). La mayor humedad acumulada por el mayor volumen de sustrato permite que un más alto número de semillas alcance rápidamente el mismo nivel de humedad y active el proceso pregerminativo y la auto reparación enzimática de las membranas celulares (Burgass \& Powell, 1984), de esta manera, se logra un aumento en la velocidad de germinación, uniformidad en la emergencia, mayor tolerancia a diferentes tipos de estrés, y reducción de la dormancia en muchas especies (Khan, 1992), es decir, se incrementa la capacidad de competencia del vegetal al momento del trasplante (Arjona et al. 1998) y, de ésta manera, el agricultor requiere de menos fertilizantes y plaguicidas en la etapa de postrasplante.

Diámetro del tallo: Los híbridos de tomate no presentaron diferencias en el diámetro de tallos; sin embargo, el tratamiento que mejor se comportó fue T14 con 1,92mm, correspondiente al híbrido Astota, con lámina de 2,2. Los tamaños de alvéolo en esta variable mostraron diferencias altamente significativas. La bandeja con mejor respuesta fue B1 (Figura 3A). Los resultados demuestran que las bandejas con alvéolos de mayor área, profundidad y volumen brindan mejores condiciones a las plántulas de tomate viéndose reflejado en el diámetro del tallo.

Según Jaramillo et al. (2006b), las bandejas de menores áreas y volúmenes tienen más pequeño el cierre del dosel, lo cual produce tallos quebradizos y más delgados, causados por elongaciones anormales, debidas a competencia intraespecífica.

El diámetro del tallo viene determinado por las alteraciones que se producen en la orientación de los microtúbulos y, por tanto, en la ordenación espacial de las microfibrillas de celulosa en la pared celular, que bajo su efecto conduce a un cambio conformacional en la estructura de las láminas celulósicas por orientación de las microfibrillas en forma longitudinal, contribuyendo así al crecimiento radial de las células (Grichko E Glick, 2001). Los elevados niveles de etileno en las plantas, se han correlacionado 
con cambios fisiológicos, dentro de los cuales se incluye el incremento del diámetro de los tallos (Marassi, 2004), fenómeno que está relacionado con la elevación del ritmo de división y subsiguiente expansión celular en los meristemos caulinares (Bleecker E Kende, 2000).

Longitud raíz principal: La longitud radicular no se afecta significativamente por las láminas de riego ni por los diferentes híbridos; no obstante, T15, cor híbrido Indaba y coeficiente 2,2 mostró la mayor longitud de raíz principal con $11,97 \mathrm{~cm}$. Esto obedece, en gran parte, al poco tiempo que tienen las plántulas para expresar el efecto de los tratamientos. B1 mostró plántulas con mayor longitud de raíz principal, seguido de B2, las cuales presentaron diferencias significativas frente a B3, y ésta mostró diferencias significativas con B4 que tuvo un menor promedio (Figura 3B).

Rodríguez et al. (2007) encontraron que en plántulas de tomate de híbrido Daniela sometidas en pretrasplante a diferentes láminas de riego, la longitud de raíz presentó el mayor valor con la lámina de 1,6 y la menor respuesta se indujo con la lámina de 0,2. Deaquiz et al. (2007) utilizaron diferentes láminas de riego $(1 ; 1,2 ; 1,4 ; \mathrm{y} 1,6$ de la evaporación) en la obtención de plántulas de tomate, aunque no encontraron diferencias significativas en la longitud de raíz principal, la mayor respuesta se debió a la lámina de 1,4.

Para hortalizas de porte alto, como el tomate, se utilizan bandejas con alvéolos de mayor capacidad, lo que permite que las plántulas posean raíces que exploren una mayor cantidad de sustrato, esto incrementa la absorción de agua situación que permite un crecimiento más eficiente de la plántula en el interior del alvéolo (Jaramillo et al. 2006b) y en el sitio definitivo en campo.

Altura: al inicio de la germinación el embrión, se desarrolla para formar una plántula iniciando la fase juvenil, donde predomina el crecimiento vegetativo, principalmente en las puntas de la raíz y el tallo (Hudson et al. 1989). La altura no presentó diferencias significativas entre las bandejas de alvéolos B2, B1, pero sí entre éstas y B3, y todas las anteriores con B4, la cual presentó la menor respuesta (Figura $3 \mathrm{C}$ ).

Los resultados indican que las mayores alturas se presentaron en bandejas con volumen alveolar más grande, esto se debe a que las plántulas tienen más

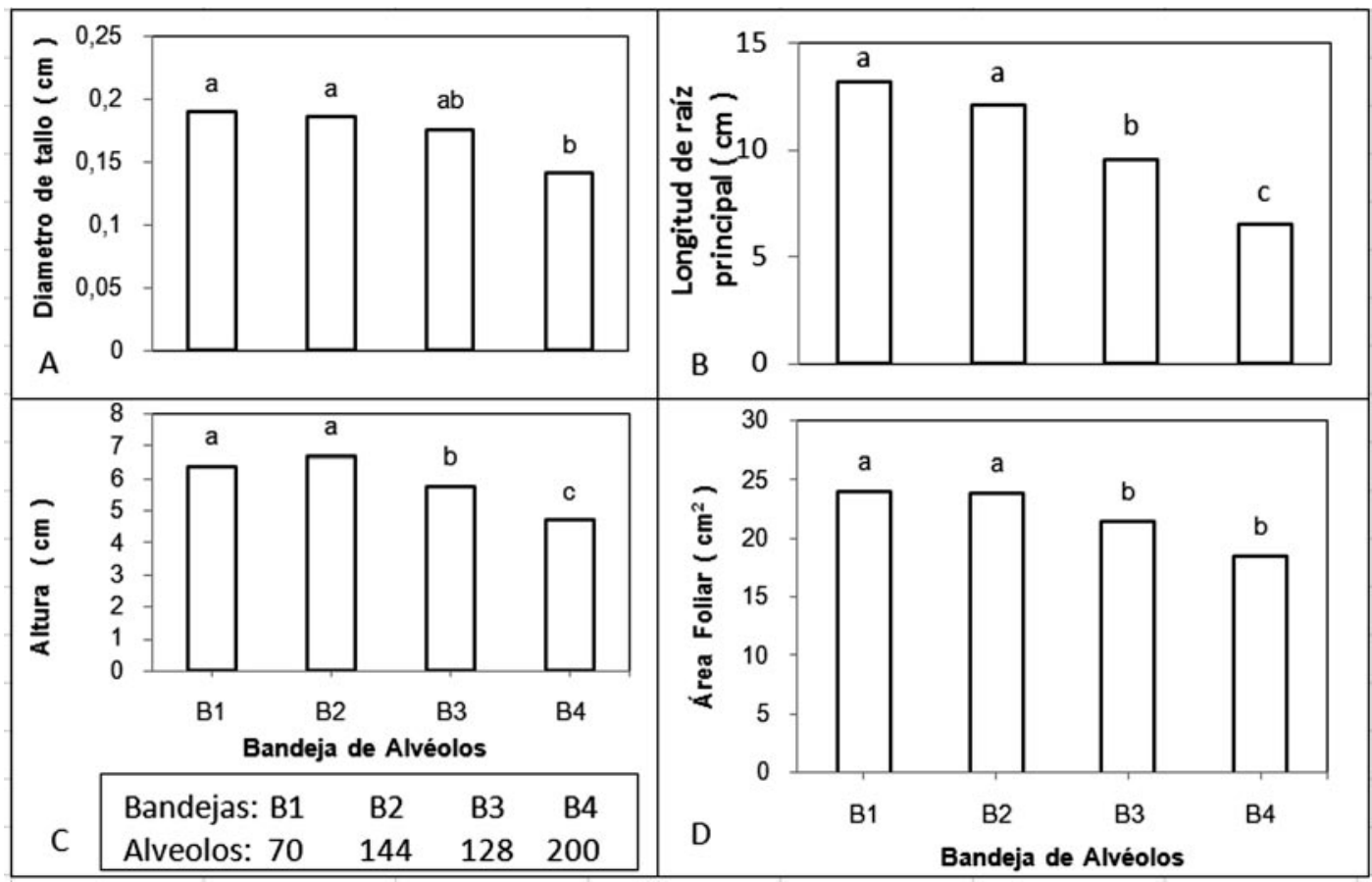

Figura 3. Diámetro de tallo, longitud de raíz principal, altura y área foliar en híbridos de tomate (L. esculentum Mill), con diferentes láminas de riego, sembrados en diversos tamaños de alvéolos. 
espacio para desarrollar su sistema radicular. Al encontrarse mayor área y profundidad de la rizosfera, se tiene mayor oportunidad de absorción de nutrientes y agua, debido a la mayor cantidad de sustrato. Acorde a lo reportado por Sarmiento et al. (2007) quienes encontraron plantas de mayor vigor sembradas en bandejas de confinamiento de 72 alvéolos. El crecimiento en altura es dependiente del aporte de agua, nutrientes, energía, espacio y aire que un medio pueda aportarle. Al ser el tallo la estructura de soporte de órganos (Scagel, 1987) requiere de condiciones tanto en el suelo como climáticas que le permitan cumplir esa función.

Área foliar: los híbridos y las láminas no indujeron diferencias estadísticas; se encontró que B1 presentó la mayor área foliar, seguida de B2, los cuales presentaron diferencias significativas con B3 y B4, respectivamente (Figura 3D). La actividad fotosintética laminar y el crecimiento están estrechamente relacionados, ya que según lo reportado por Fogg (1967), la cantidad de fotosíntesis que una planta realiza depende de la superficie de la hoja, de los órganos fotosintéticos que posea y de la actividad fotosintética por unidad de área de estos tejidos y de la duración de este proceso. Al mismo tiempo, el área foliar depende del número de hojas, de su velocidad de crecimiento y de su tamaño final (Barraza et al. 2004).

Barraza et al. (2004) encontraron que plantas de tomate sembradas a diferentes densidades mostraron un aumento en al área foliar con el aumento en la densidad; el comportamiento de la materia seca a incrementos de densidad de población depende en gran medida del área foliar y, a su vez, según Jarma et al. (1999), las plantas con mayor área foliar fotosintéticamente activa y ambiente favorable son capaces de utilizar mejor la energía solar con una fotosíntesis más eficiente.

Fitomasa fresca y seca de raíz, tallo y hojas: la variable fitomasa fresca presentó diferencias a nivel de raíz, tallo, hojas y total. El tratamiento con la mayor respuesta fue el T14, excepto para peso total (T16); en todos los casos la menor Fitomasa fresca fue obtenida con el T1 (Figura 4B).

El tamaño de alvéolo presentó diferencias estadísticas en todos los casos; B1 mostró el mejor comportamiento con diferencias significativas respecto a las demás bandejas y B4 arrojó los valores menos favorables (Figura 4A). La fitomasa seca total no tuvo diferencias significativas entre tratamientos, pero sí se presentaron en raíz tallo y hojas. T8 manifestó el mayor peso seco en raíz y tallo, mientras que para hojas fue T16. Para peso seco total y de hojas T1 tuvo los valores más bajos, respecto a tallos y raíz, el menor peso se logró con T5 y T10, respectivamente (Figura 4B). En cuanto a tamaño de alvéolo, se observó claramente que aumentó el peso seco al aumentar el tamaño de alvéolo, con diferencias significativas (Figura 4A).

Las bandejas con mayor área alveolar presentaron una mayor masa fresca, debido a que estas bandejas garantizan un buen anclaje radicular que permite mayor vigor de plántulas y, consecuentemente, mayor acumulación de osmolitos, que garantizan un mejor crecimiento $\mathrm{y}$, por lo tanto, mayor producción de fotoasimilados y de fitomasa fresca (Salisbury $\&$ Ross, 1994).

Los resultados anteriores demuestran que la cantidad de agua influye directamente en el peso seco de las hojas, de igual forma un mayor peso seco genera un mayor potencial hídrico, lo que implica que el agua dentro de los tejidos estará retenida en mayor cantidad y con mayor fuerza (Azcón-Bieto \& Talon, 1993)

Según Hunt (1982), un mayor aprovechamiento de la radiación solar por parte del follaje se manifiesta en un mayor crecimiento general de las plantas, mayor acumulación de materia seca y mayor rendimiento total.

El peso fresco depende considerablemente de la lámina aplicada y es muy sensible a bajos contenidos de humedad en el suelo. Láminas de 0,2 evaluadas por Rodríguez et al. (2007) mostraron la menor respuesta en el peso fresco de plántulas de tomate e igualmente en el peso seco, mientras que la lámina de 1,6 indujo el mayor peso fresco a nivel de raíz. 


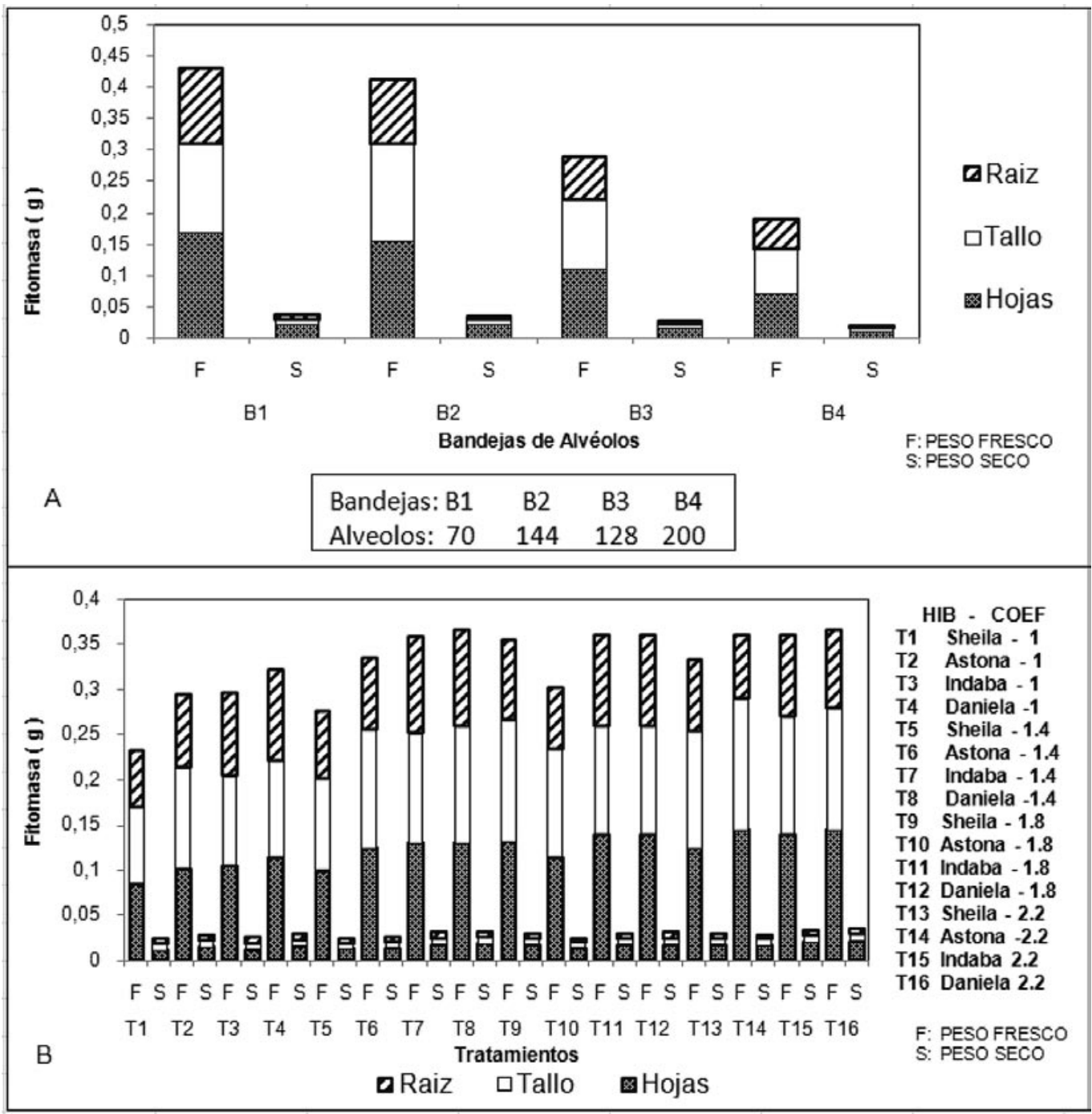

Figura 4. Fitomasa fresca y seca de tallo, hojas, raíz y total de híbridos de tomate (L. esculentum Mill), con diferentes láminas de riego, sembrados en diversos tamaños de alvéolos.

\section{CONCLUSIONES}

Los procesos de germinación, aunque están determinados genéticamente, son más eficientes con buenos contenidos de humedad, los cuales están dados por mayores láminas de riego y alvéolos con mayor capacidad de almacenamiento de sustrato.

Las plántulas de tomate de mayor altura y área foliar, se obtuvieron con bandejas de germinación 144 alvéolos, mientras que el mayor peso fresco y seco se logró con bandejas de de 72 alvéolos y en todos los casos con un coeficiente multiplicador de la evaporación de 2.2.

\section{BIBLIOGRAFÍA}

ARJONA, H.; GUERRERO, A.; PRIETO, C. 1998. Estudios de osmoiniciación de semillas de cebolla de bulbo Allium cepa L. Agronomía Colombiana 15(2):143-152.

AZCÓN-BIETO, J.; TALON, M. 1993. Fisiología y Bioquímica Vegetal. McGraw Hill/Interamericana, Barcelona. 759p.

BARRAZA, F.V.; FISCHER, G.; CARDONA C., E. 2004. Estudio del proceso de crecimiento del cultivo 
del tomate (L. esculentum Mill.) en el Valle del Sinú medio, Colombia. Agronomía Colombiana. 22(1):81-90.

BLEECKER, A.B.; KENDE, H. 2000. Ethylene: A gaseosus signal molecular in plant. Annu. Rev. Cell. Dev. Biol. 16:1-18.

BURGAS, R.; POWELL, A. 1984. Evidence for repair processes in the invigoration of seeds by hydration. Ann. Bot. 53:753-757.

CASTILLA, P.N. 1995. Manejo del cultivo intensivo con suelo. En: Nuez V, F.; Rodríguez del Rincón, A.; Tello, J.; Cuartero, J.; Segura, B. eds. El cultivo del tomate. Ediciones Mundi-Prensa. Madrid. España. p.189-226.

CHEN, F.; BRADFORD, K.J. 2000. Expansins as agents in hormone action. En: Davies, P. (Ed.). Plant hormones. Ed. Kluner Academis Publishers. (EEUU). p.262-281.

DEAQUIZ, Y.; ÁLVAREZ-HERRERA, J.; FRAILE, A.L. 2007. Efecto de diferentes láminas de riego y sustratos en la propagación de híbridos de tomate (L. esculentum Mill). En: Fischer, G.; Magnitskiy, S.; Flórez, L.; Miranda, D.; Medina, A. (Eds). Memorias II Congreso Colombiano de Horticultura. Ed. Produmedios. Bogotá. p.178.

EL SEMILLERO. Disponible en: http://www.elsemillero. net. /Insumos /bandejas.htm. [Julio 25, 2007].

FERNÁNDEZ-BRAVO, C.; URDANETA, N.; SILVA, W.; POLISZUK, H.; MARÍN, M. 2006. Germinación de semillas de tomate (L. esculentum Mill.) cv Río Grande sembradas en bandejas plásticas, utilizando distintos sustratos. Rev. Fac. Agron. (Venezuela) 23(2):188-196.

FOGG, G.E. 1967. El crecimiento de las plantas. Editorial Universitaria de Buenos Aires (EUDEBA). 327p.

GONZÁLEZ M., A.; HERNÁNDEZ L., B.A. 2000. Estimación de las necesidades hídricas del tomate. TERRA Latinoamericana. 18(1):45-50.
GRICHKO, V.P.; GLICK, B.R. 2001. Ethylene and flooding stress in plants. Plant Physiol. Biochem. 39:1-9.

HUDSON, T.; HARTMANN, D.; KESTE, E. 1989. Propagación de plantas. Principios y prácticas. $3^{\mathrm{a}} \mathrm{ed}$. Comp. Ed. Continental S.A. México, 758p.

HUNT, R. 1982. Plant growth curves. The functional approach to plant growth analysis. Edward Arnold Publishers Ltd., Londres. 67p.

JARAMILLO, J.; RODRÍGUEZ, V.; GUZMÁN, M.; ZAPATA, M. 2006a. El cultivo de tomate bajo invernadero. CORPOICA C. I. La Selva y MINAGRICULTURA. Colombia. Boletín Técnico No. 21. 48p.

JARAMILLO, J.; DÍAZ, C.A.; SÁNCHEZ, L., G.D.; TAMAYO, M., P.J. 2006b. Manejo de semilleros de hortalizas. CORPOICA C. I. La Selva y MINAGRICULTURA. Colombia. Boletín Técnico No. 8. 52p.

JARMA, A.; BUITRAGO, C; GUTIÉRREZ, S. 1999. Respuesta del crecimiento de la habichuela (Phaseolus vulgaris $\mathrm{L}$. var. BlueLake) a tres niveles de radiación incidente. COMALFI 26(1-3):62-73.

KHAN, A. 1992. Preplant physiological seed conditioning. Horticultural Reviews 14:131-181.

MANJARREZ, J.R.S. 1980. Riegos. El cultivo del tomate para consumo fresco en el valle de Culiacán. CEVAS-CIAPAN-SARH. 225p.

MARASSI, M. A. 2004. Hormonas vegetales. Hipertextos de área de Biología. Argentina. Disponible desde Internet en: http://fai.unne.edu.ar/biologia/ plantas/hormonas.htm >. (Con acceso 28/07/07).

MONDOÑEDO, J.R. 1984. Manuales para educación agropecuaria. Tomates. Ed. Trillas. México $4^{\mathrm{a}}$ ed. $141 \mathrm{p}$.

OBSERVATORIO DE FINANZAS RURALES. TOMate. Disponible en: http://www.agronet.gov.co/ www/htm3b/excepciones/cargaNet/netcarga16. aspx?cod $=16 \varepsilon$ reporte $=$ Producci\%u00f $3 n+$ na cional + por + producto\&file $=2007816102236$ 20058417048_agronetevaarearendimientoypro- 
duccionpor producto poragno.rptEcódigo $=16 \mathcal{E}$ xcepcion $=1$ Efechal $=2005$ Eproducto $=$ Tomate\& Fecha $\mathrm{F}=2005$. (con acceso 28/07/07).

PÉREZ-GARCÍA, F.; MARTÍNEZ-LABORDE, J.B. 1994. Introducción a la Fisiología Vegetal. Ed. MundiPrensa. (Madrid). 218p.

RODRÍGUEZ, J., D.; BALAGUERA, H.E.; ÁLVAREZ-HERRERA, J. 2007. Efecto del déficit de agua en el trasplante de plántulas de tomate. En: Fischer, G.; Magnitskiy, S.; Flórez, L.; Miranda, D.; Medina, A. (Eds). Memorias II Congreso Colombiano de Horticultura. Ed. Produmedios. Bogotá. p.177.

SARMIENTO, G.; DEAQUIZ, Y.; ÁLVAREZ-HERRERA, J. 2007. Tamaños de alvéolo e imbibición en agua en la germinación de semillas de tomate. En: Fischer, G.; Magnitskiy, S.; Flórez, L.; Miranda, D.; Medina,
A. (Eds). Memorias II Congreso Colombiano de Horticultura. Ed. Produmedios. Bogotá. p.180.

SCAGEL, R.F. 1987. El reino vegetal. Amplio compendio de Botánica con numerosas referencias a la reproducción vegetal. Barcelona. Ed. Omega, S.A., $2^{\text {a }}$ ed. $778 p$.

SALISBURY, F.B.; ROSS, C.W. 1994. Fisiología vegetal. Grupo Editorial Iberoamérica S.A., México. 759p.

TALON, M. 1993. Giberelinas. En: Azcón-Bieto, J.; Talon, M. (eds). Fisiología y Bioquímica Vegetal. McGraw Hill/Interamericana, Barcelona. p.301-318.

Recibido: Noviembre 26 de 2007

Aceptado: Julio 16 de 2008 